\title{
Actividad antimicrobiana de actinomycetes aislados desde ambientes acuáticos del sur de Chile
}

\author{
Sergio Leiva Pla, Marisa Yáñez $\mathbf{S}^{1 \mathbf{b}}$, Luis Zaror $\mathbf{C}^{2 c}$, \\ Héctor Rodríguez $\mathbf{S}^{1 b}$, Héctor $\mathbf{G}$ arcía-Q uintanalc. \\ Antimicrobial activity of \\ actinomycetes isolated from aquatic \\ environments in Southern Chile
}

Background: The easy access and inappropriate use of antimicrobials led to selection and spread of resistant microorganisms strains. It is imperative to search for new and more effective antimicrobials. One strategy is the screening of metabolites produced by microorganisms found in the environment. Actinomycetes are a potential source of new drugs. Aim: To isolate actinomycetes from sediments of Chilean rivers and lakes and to screen them for antimicrobial activity against reference bacterial strains and pathogenic fungi. Material and Methods: Actinomycetes were isolated from sediment samples, using caseinstarch agar. The antimicrobial activity against 3 bacterial species and 7 fungal species was tested using the disc diffusion method. For the extraction of active metabolites, culture broths of antagonistic actinomycetes were extracted with organic solvents followed by testing the antibiotic activity. Results: A total of 62 strains of actinomycetes were isolated, mainly Streptomyces sp (83.9\%). Thirty six strains (58.1\%) showed antimicrobial activity, mainly against Bacillus subtilis and Candida albicans. Some isolates inhibited a wide spectrum of indicator strains, like LRI 4A strain (Streptomyces sp) that inhibited Bacillus subtilis, Candida albicans and 4 filamentous fungi. Conclusions: Lakes and rivers of Southern Chile are an important reservoir of antagonistic actinomycetes, a potential source of new drugs (Rev Méd Chile 2004; 132: 151-9). (Key Words: Actinomycetaceae; Antibiotics, antifungal; Antibiotics, combined; Streptomyces)

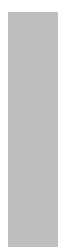

Recibido el 18 de junio, 2003. Aceptado en versión corregida el 8 de octubre, 2003.

${ }^{1}$ Instituto de Microbiología, Facultad de Ciencias, 2Instituto de Microbiología Clínica, Facultad de Medicina, Universidad Austral de Chile.

Trabajo financiado por los Proyectos DID S-1999-33 y DID S-2002-26.

a Biólogo Marino, Magíster en Ciencias

b Tecnólogo Médico

c Doctor en Ciencias

Correspondencia a: Héctor García-Quintana. Instituto de Microbiología, Facultad de Ciencias, Universidad Austral de Chile. Casilla 167. Valdivia, Chile. Fax: 63 215295. E mail: sleiva@uach.cl 
$\mathrm{E}^{1}$ fácil acceso y el uso inapropiado de fármacos para combatir las infecciones causadas por microorganismos patógenos, promueve la autoprescripción, lo que facilita la selección, persistencia y diseminación de microorganismos resistentes ${ }^{1}$. Se acepta que hay una relación establecida, pero compleja, entre el consumo humano de agentes antimicrobianos y la prevalencia de la resistencia a las drogas en los patógenos. Varios factores influyen en la frecuencia variable de la resistencia en diferentes ecosistemas, tales como: notable plasticidad genética de los microorganismos, reservorios humanos o ambientales donde pueden persistir o ser transmitidos genes de resistencia u organismos resistentes, presiones selectivas por el uso aumentado e inapropiado de antibióticos, así como cambios sociales y tecnológicos que afectan la transmisión de los organismos. Si a esto se suma el aumento de pacientes inmunocomprometidos y de tratamientos con drogas inmunosupresoras, es entendible el incremento $\mathrm{y}$ emergencia de infecciones bacterianas $\mathrm{y}$ fúngicas $^{2-4}$.

Aunque la prevalencia de la resistencia a las drogas en los hongos es baja en relación a las bacterias, se estima que las presiones selectivas llevarán a una disminución en la susceptibilidad y a un aumento en la resistencia a los actuales tratamientos antifúngicos ${ }^{5}$. La más frecuente es la resistencia de Candida spp a los azoles, pero la resistencia primaria in vitro a anfotericina B también se ha observado en hongos filamentosos emergentes como: Scedosporium spp, Fusarium spp, Aspergillus terreus, en algunas levaduras como Trichosporon spp, Candida lusitaniae, C guilliermondi y con menor frecuencia en Cryptococcus neoformans ${ }^{6}$. Actualmente se usan varias estrategias para controlar las micosis resistentes; éstas incluyen: aumento de la intensidad de la dosis de la droga, terapia antifúngica de combinación e inmunomodulación ${ }^{6,7}$. Sin embargo, la pesquisa de nuevos antifúngicos continúa siendo una necesidad imperiosa. La emergencia de cepas de hongos resistentes ha creado mayor demanda por nuevas drogas, sobre todo para el tratamiento de micosis sistémicas.

La pasada década fue testigo del notable incremento en el arsenal de nuevos antifúngicos, aunque persisten debilidades como: sus espectros, potencias, seguridad y propiedades farmacocinéticas ${ }^{8}$.
Si bien la síntesis química de drogas es una opción válida, la búsqueda de compuestos a partir de microorganismos continúa siendo la principal fuente de nuevos antimicrobianos.

Desde la segunda mitad del siglo XX se ha informado cerca de 50.000 productos naturales provenientes de microorganismos, de los cuales más de 10.000 son biológicamente activos y más de 8.000 son agentes antibióticos y antitumorales ${ }^{9}$. Los principales productores de estos metabolitos son bacterias del suelo del orden Actinomycetales ${ }^{10}$, de cuyos cultivos se han aislado importantes agentes terapéuticos, como estreptomicina, aminoglucósidos, macrólidos y tetraciclinas.

Los actinomycetes son bacterias filamentosas Gram positivas, abundantes en suelos, pero también encontradas en ambientes acuáticos dulceacuícolas y marinos ${ }^{10-13}$. Las bacterias del suelo siguen siendo estudiadas, pero hay una notable merma en el hallazgo de nuevos productos, estimándose que más de $90 \%$ de los cultivos bioactivos descubiertos producen agentes ya informados o son variaciones menores de uno ya descrito $^{9}$. Por ello, la pesquisa se ha reorientado hacia otros ambientes, como son: los sedimentos de ríos, lagos y océanos, así como plantas y animales acuáticos, que ofrecen la posibilidad de encontrar cepas silvestres no descritas que produzcan nuevos metabolitos secundarios farmacológicamente activos ${ }^{9,13-17}$. La lista de compuestos obtenidos a partir de microorganismos acuáticos incluyen: antimicrobianos, anticancerígenos y antiinflamatorios, muchos de los cuales pertenecen a clases químicas no descritas en microorganismos terrestres, estando algunos de ellos ya en etapa de evaluación clínica $9,13,16$.

Debido a que los ecosistemas acuáticos difieren notablemente de los terrestres, se espera que las capacidades metabólicas y fisiológicas de los microorganismos acuáticos sean diferentes a las de sus contrapartes terrestres, lo que ofrece un enorme potencial de descubrimiento de nuevas drogas. Esto podría determinar que los actinomycetes en su proceso de adaptación al ambiente acuático, hayan desarrollado habilidades estratégicas que les otorgan mayores probabilidades de supervivencia, entre las cuales la producción de metabolitos bioactivos en contra de otras bacterias, hongos y otros organismos es una probabilidad cierta. 
Sin duda que, un uso más racional de los antimicrobianos disponibles demorará o evitará la emergencia de cepas resistentes, lo que está en concordancia con las políticas de uso de antimicrobianos en Chile ${ }^{18}$.

El objetivo de esta investigación es explorar la actividad antibacteriana y antifúngica de los actinomycetes de sedimentos de ríos y lagos del sur de Chile. La elección de los lagos se hizo en consideración a factores como: aislamiento geográfico de los sitios de muestreo y poca intervención antrópica en estos lugares.

\section{Material y MÉtodos}

Muestreo. Se obtuvieron muestras de sedimentos de 8 esteros y ríos tributarios del lago Riñihue y de 4 lagos de la X Región: Riñihue, Tarahuín, Natri, Tepuhueico (Figura 1). Mediante draga Eckman se recolectó sedimento a diferentes profundidades (1 a $200 \mathrm{~m}$ ). Los sitios se eligieron por su alejamiento de centros poblados, casi nula contaminación y absoluto desconocimiento de la microbiota que poseen. Las muestras transportadas en frascos estériles y cajas térmicas a $4^{\circ} \mathrm{C}$ se procesaron inmediatamente en el Instituto de Microbiología de la Universidad Austral de Chile.

Aislamiento e identificación de actinomycetes. Las muestras de sedimento se mantuvieron en baño de agua a $50^{\circ} \mathrm{C}$ por $1 \mathrm{~h}$. Este tratamiento es efectivo para reducir el número de bacterias no deseadas, favoreciendo el crecimiento de los actinomycetes $^{19,20}$. Diluciones de las muestras se sembraron en triplicado en placas de agar caseínaalmidón, suplementadas con nistatina y cicloheximida (25 y $10 \mu \mathrm{g} \cdot \mathrm{mL}^{-1}$, respectivamente) para inhibir el crecimiento de hongos ${ }^{20,21}$ y se incubaron a $20^{\circ} \mathrm{C}$ por al menos 28 días. Los aislamientos se preservaron a $4^{\circ} \mathrm{C}$ en agar extracto de levaduraextracto de malta (YMA) inclinado hasta su identificación y ensayos de antagonismo. Las cepas se identificaron hasta nivel de género siguiendo los esquemas de Holt et $\mathrm{al}^{22}$.

Ensayos de actividad antimicrobiana. La actividad antagónica se determinó mediante la técnica de difusión en disco, que consiste en cultivar los actinomycetes en agar YMA por 10 días y luego transferir 3 discos (11 mm de diámetro) sobre agar Mueller Hinton (Difco) previamente sembrados

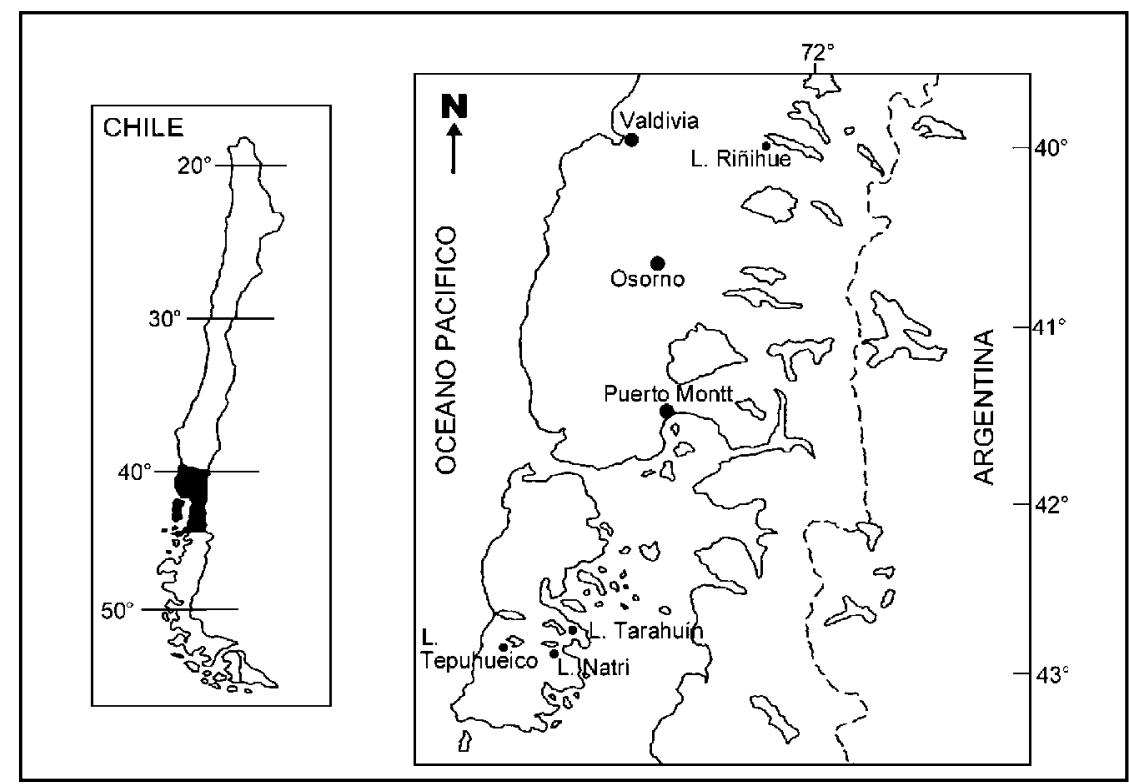

Figura 1. Localización de los 4 lagos muestreados en la X región. 
con suspensiones de aproximadamente $10^{6} \mathrm{ufc} /$ $\mathrm{mL}$ de las cepas de prueba: Escherichia coli ATCC 25922, Staphylococcus aureus ATCC 25923 y Bacillus subtilis ATCC 6639 y sobre agar Sabouraud dextrosa (Difco) previamente sembrado con una suspensión de la misma densidad de Candida albicans LT1. En placas incubadas a $20^{\circ} \mathrm{C}$ por $24 \mathrm{~h}$ se midió el diámetro de los halos de inhibición. Además, se probó la actividad antifúngica de las cepas de actinomycetes con mayor espectro de actividad sobre aislados clínicos de los hongos filamentosos: Trichophyton rubrum, Trichophyton mentagrophytes, Aspergillus fumigatus, Microsporum canis y Alternaria tenuis y la levadura Cryptococcus neoformans, siguiendo los procedimientos de Zaror y Espinel-Ingroff ${ }^{23}$.

Extracción de los compuestos activos y prueba de su actividad antagónica. Las cepas que mostraron mayor actividad se cultivaron en agar YMA a $20^{\circ} \mathrm{C}$ por 10 días. Trozos del agar con crecimiento, se homogeneizaron e inocularon en $2 \mathrm{~L}$ de un medio de producción (extracto de malta 1\%, extracto de levadura $0,4 \%$, dextrosa $0,4 \%, \mathrm{pH}=7,2$ ) y se cultivaron bajo agitación continua a $20^{\circ} \mathrm{C}$ por 20 días. Luego, el caldo se filtró y se trató con 5 solventes orgánicos de polaridad creciente, partiendo por éter de petróleo, luego cloroformo, etilmetilcetona, etilacetato y butanol; posteriormente las fases orgánicas se evaporaron en rotavapor hasta sequedad y los residuos se resuspendieron en metanol. La extracción de los compuestos activos fue seguida por ensayos de actividad antimicrobiana. Para ello, discos de papel filtro de $6 \mathrm{~mm}$ de diámetro se impregnaron con $20 \mu \mathrm{L}$ del residuo resuspendido de cada extracto y se depositaron sobre placas con agar Mueller Hinton previamente sembradas con las cepas de referencia de E coli, S aureus, B subtilis y agar Sabouraud dextrosa con $\mathrm{C}$ albicans y $\mathrm{C}$ neoformans. Como control negativo se impregnaron discos sólo con $20 \mu \mathrm{L}$ de metanol y se dejaron evaporar previo a su uso.

\section{Resultados}

Desde las muestras se obtuvieron 62 cepas de actinomycetes. De ellas, 52 (83,9\%) correspondieron a Streptomyces spp, en tanto que 3 cepas se identificaron como Micromonospora spp (4,8\%), 2 cepas como Micropolyspora spp $(3,2 \%)$ y 5 no se lograron identificar (8,1\%). A cada una se le asignó una clave y se traspasaron a cepario. Esta clave comesponde a las siglas LRI-№ de aislamiento o AR-№ de aislamiento.

De las 62 cepas aisladas, 36 (58,1\%) tuvieron actividad antimicrobiana. El análisis del espectro antimicrobiano proporciona información sobre los patrones de inhibición (Figura 2). La actividad se

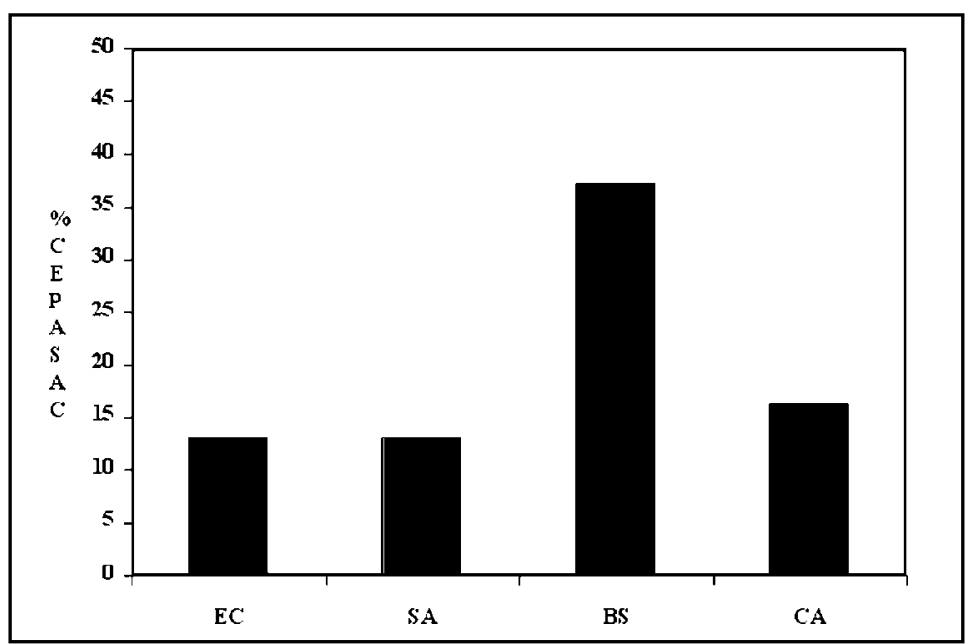

Figura 2. Especies bacterianas y fúngicas inhibidas por Actinomycetes acuáticos. EC, Escherichia coli ATCC 25922; SA, Staphylococcus aureus ATCC 25923; BS, Bacillus subtilis ATCC 6639; CA, Candida albicans LT1. 
Tabla 1. Actividad antimicrobiana de Actinomycetes acuáticos bioactivos contra cepas de referencia

\begin{tabular}{|c|c|c|c|c|c|}
\hline \multirow[t]{2}{*}{ Cepa } & \multirow[t]{2}{*}{ Identificación } & \multicolumn{4}{|c|}{ Tapiz indicador } \\
\hline & & Saureus & B subtilis & E coli & $\mathrm{C}$ albicans \\
\hline LRI $1 \mathrm{~A}$ & Micropolyspora sp & 0 & 25 & 24 & 0 \\
\hline LRI 2A & Micromonospora sp & 0 & 0 & 0 & 15 \\
\hline LRI 4A & Streptomyces sp & 0 & 20 & 0 & 40 \\
\hline LRI 5A & Streptomyces sp & 21 & 22 & 0 & 15 \\
\hline LRI 9A & Streptomyces sp & 14 & 0 & 0 & 0 \\
\hline LRI 10A & Streptomyces sp & 15 & 0 & 0 & 0 \\
\hline LRI 13A & Streptomyces sp & 0 & 0 & 0 & 15 \\
\hline LRI 14A & Streptomyces sp & 0 & 15 & 0 & 20 \\
\hline LRI 15A & Streptomyces sp & 0 & 24 & 24 & 16 \\
\hline LRI 16A & Streptomyces sp & 0 & 28 & 30 & 0 \\
\hline LRI 22A & Streptomyces sp & 0 & 17 & 0 & 0 \\
\hline LRI 25A & Streptomyces sp & 0 & 0 & 20 & 0 \\
\hline LRI 26A & Streptomyces sp & 0 & 0 & 26 & 0 \\
\hline LRI 29A & Streptomyces sp & 25 & 0 & 28 & 0 \\
\hline LRI 36A & Streptomyces sp & 18 & 0 & 0 & 0 \\
\hline LRI 39A & Streptomyces sp & 0 & 27 & 0 & 0 \\
\hline LRI 41A & Streptomyces sp & 0 & 23 & 0 & 0 \\
\hline LRI 42A & Streptomyces sp & 0 & 30 & 0 & 0 \\
\hline LRI 46A & Streptomyces sp & 0 & 29 & 25 & 0 \\
\hline LRI 48A & Streptomyces sp & 0 & 15 & 0 & 0 \\
\hline LRI 49A & Streptomyces sp & 0 & 16 & 0 & 0 \\
\hline LRI 50A & Streptomyces sp & 0 & 0 & 0 & 18 \\
\hline LRI 51A & Streptomyces sp & 0 & 0 & 0 & 17 \\
\hline LRI 53A & Streptomyces sp & 0 & 27 & 0 & 0 \\
\hline LRI 55A & Streptomyces sp & 0 & 20 & 0 & 0 \\
\hline LRI 56A & Streptomyces sp & 0 & 20 & 0 & 0 \\
\hline LRI 60A & Streptomyces sp & 0 & 25 & 0 & 0 \\
\hline LRI 61A & Streptomyces sp & 0 & 25 & 0 & 0 \\
\hline LRI 64A & Streptomyces sp & 0 & 0 & 0 & 16 \\
\hline LRI 65A & Streptomyces sp & 0 & 18 & 0 & 0 \\
\hline LRI 67A & Streptomyces sp & 19 & 0 & 0 & 0 \\
\hline LRI 69A & Streptomyces sp & 0 & 25 & 0 & 0 \\
\hline AR 131 & Streptomyces sp & 29 & 20 & 15 & 18 \\
\hline AR 163 & Streptomyces sp & 0 & 17 & 0 & 0 \\
\hline AR 165 & Streptomyces sp & 0 & 18 & 0 & 0 \\
\hline AR 213 & Streptomyces sp & 18 & 0 & 0 & 0 \\
\hline № caso & & 8 & 23 & 8 & 10 \\
\hline
\end{tabular}

La actividad antimicrobiana se expresa como el diámetro del halo de inhibición (mm) alrededor de un disco de agar con la cepa viva después de una incubación a $23^{\circ} \mathrm{C}$ por $16-18 \mathrm{~h}$.

dirigió principalmente contra B subtilis, que fue inhibido por 23 cepas (37,1\%). En contraste, sólo 8 cepas $(12,9 \%)$ presentaron actividad contra E coli.
El detalle de la actividad antimicrobiana de 36 cepas de actinomycetes sobre las tres cepas bacterianas y una cepa fúngica se muestra en la Tabla 1. 
Se destacan los Streptomyces nativos: LRI 5A que inhibió tanto a las bacterias Gram positivas B subtilis y $\mathrm{S}$ aureus así como al hongo $\mathrm{C}$ albicans; LRI-15A, LRI-16A, LRI-29A y LRI-46A inhibieron tanto a Gram positivos como Gram negativos y AR131 presentó actividad contra todas las cepas indicadoras. Por su parte la Micropolyspora LRI-1A actuó sobre B subtilis y E coli.

Se escogieron 13 cepas con el mayor espectro de actividad para determinar su efecto contra hongos filamentosos y levaduriformes. Los resultados se muestran en la Tabla 2. Bajo las condiciones experimentales utilizadas, los únicos aislados que presentaron actividad fueron LRI-5A que inhibió a A tenuis, LRI-4A con moderada actividad contra A tenuis y T rubrum y fuerte antagonismo contra $\mathrm{M}$ canis y T mentagrophytes y la cepa LRI$15 \mathrm{~A}$ que inhibió a $\mathrm{C}$ neoformans. A fumigatus nunca fue inhibida.

Los extractos de 13 cepas elegidas obtenidos con distintos solventes orgánicos se ensayaron contra 5 cepas de prueba. La actividad de estos extractos se muestra en la Tabla 3. De un total de 325 ensayos, 96 (29,5\%) fueron positivos inhibiendo a alguna de las 5 cepas indicadoras. La mayor actividad de los extractos fue contra Gram positivos, siendo B subtilis la cepa más sensible con 45 ensayos positivos (46,9\% del total de ensayos positivos). Por el contrario, C neoformans y C albicans fueron las más resistentes, con sólo uno y tres ensayos positivos, respectivamente. Los extractos más activos fueron los obtenidos con etilmetilcetona, con 28 ensayos positivos $(29,2 \%$ del total de ensayos positivos), mientras que las fracciones menos activas fueron las provenientes de cloroformo con sólo 11,5\% de actividad.

\section{DisCUSIÓN}

En esta investigación se logró el aislamiento de actinomycetes a partir de muestras de sedimento de 8 esteros y ríos tributarios del lago Riñihue y del propio lago y de tres lagos de Chiloé (Natri,

Tabla 2. Actividad antifúngica de 13 cepas de Actinomycetes seleccionados

\begin{tabular}{|c|c|c|c|c|c|c|c|}
\hline \multirow[t]{2}{*}{ Cepa } & \multirow[t]{2}{*}{ Identificación } & \multicolumn{6}{|c|}{ Tapiz indicador } \\
\hline & & $\mathrm{AF}$ & $\mathrm{AT}$ & $\mathrm{MC}$ & $\mathrm{TM}$ & $\mathrm{TR}$ & $\mathrm{CR}$ \\
\hline LRI $1 \mathrm{~A}$ & Micropolyspora sp & 0 & 0 & 0 & 0 & 0 & 0 \\
\hline LRI 4A & Streptomyces sp & 0 & 20 & 45 & 60 & 20 & 0 \\
\hline LRI 5A & Streptomyces sp & 0 & 20 & 0 & 0 & 0 & 0 \\
\hline LRI 14A & Streptomyces sp & 0 & 0 & 0 & 0 & 0 & 0 \\
\hline LRI 15A & Streptomyces sp & 0 & 0 & 0 & 0 & 0 & 40 \\
\hline LRI 16A & Streptomyces sp & 0 & 0 & 0 & 0 & 0 & 0 \\
\hline LRI 25A & Streptomyces sp & 0 & 0 & 0 & 0 & 0 & 0 \\
\hline LRI 26A & Streptomyces sp & 0 & 0 & 0 & 0 & 0 & 0 \\
\hline LRI $46 \mathrm{~A}$ & Streptomyces sp & 0 & 0 & 0 & 0 & 0 & 0 \\
\hline LRI 55A & Streptomyces sp & 0 & 0 & 0 & 0 & 0 & 0 \\
\hline LRI 56A & Streptomyces sp & 0 & 0 & 0 & 0 & 0 & 0 \\
\hline LRI 60A & Streptomyces sp & 0 & 0 & 0 & 0 & 0 & 0 \\
\hline LRI 61A & Streptomyces sp & 0 & 0 & 0 & 0 & 0 & 0 \\
\hline
\end{tabular}

La actividad antimicrobiana se expresa como el diámetro del halo de inhibición (mm) alrededor de un disco de agar con la cepa viva después de una incubación a $23^{\circ} \mathrm{C}$ por $16-18 \mathrm{~h}$. AF, Aspergillus fumigatus; AT, Alternaria tenuis; MC, Microsporum canis; TM, Trichophyton mentagrophytes; TR, Trichophyton rubrum; CR, Cryptococcus spp. 

Tabla 3. N úmero de ensayos positivos con los extractos de 13 cepas de Actinomycetes
sobre 3 especies bacterianas y 2 fúngicas (325 ensayos)

\begin{tabular}{|lrrrrrrrr|}
\hline \multirow{2}{*}{ Cepa indicadora } & \multicolumn{2}{c}{ Extractos } & & & & & \multicolumn{2}{c|}{ Total positivos } \\
& \multicolumn{1}{c}{ EP } & CL & ET & EA & BU & № & $\%$ \\
\hline S aureus & 8 & 6 & 10 & 11 & 5 & 40 & 61,5 \\
B subtilis & 11 & 3 & 12 & 11 & 8 & 45 & 69,2 \\
E coli & 0 & 0 & 6 & 1 & 0 & 7 & 10,8 \\
C albicans & 2 & 1 & 0 & 0 & 0 & 3 & 4,6 \\
C neoformans & 0 & 1 & 0 & 0 & 0 & 1 & 1,5 \\
\hline Total & 21 & 11 & 28 & 23 & 13 & 96 & 29,5 \\
\hline
\end{tabular}

ET, éter de petróleo; CL, cloroformo; ET, etilmetilcetona; EA, etilacetato; BU, butanol.

Tarahuín y Tepuhueico). Trabajos anteriores de Roubillard ${ }^{24}$, Lazo $^{25}$ y García-Quintana et $\mathrm{al}^{26}$, entre otros, habían demostrado la presencia de actinomycetes en la microbiota de suelos y aguas de diversas zonas de Chile. En otros países diversos investigadores habían informado el hallazgo de actinomycetes en suelos y aguas, evaluando su potencial productor de agentes bioactivos ${ }^{17,27-30}$.

Según Nolan y Cross $^{31}$ la disminución de la tasa de descubrimiento de nuevas cepas productoras a partir de cepas terrestres, incitó a explorar nuevos hábitats con el objeto de aislar cepas no descritas con antelación y que pudiesen producir metabolitos con estructuras y actividades diferentes que se aprovechasen en el área terapéutica.

Del total de aislamientos obtenidos, 62 cepas fueron identificadas como actinomycetes y de ellas 52 correspondieron a Streptomyces spp (83,9\%) lo cual concuerda con lo informado en otras latitudes para ambientes dulceacuícolas ${ }^{10,17,32}$. También se identificaron tres cepas como Micromonospora spp (4,8\%) y dos como Micropolyspora spp (3,2\%). Las cinco cepas restantes no pudieron ser identificadas, pero presumiblemente podrían corresponder a géneros de actinomycetes signados como raros, como: Actinomadura, Actinoplanes, Dactylosporangium o Streptosporangium. El bajo número de aislamiento de estos actinomycetes raros se debería a que su aislamiento implica: desarrollo de medios de cultivo especializados, empleo de pretratamientos de la muestra y tiempos de incubación más prolongados o bien necesidad del uso de antibacterianos que inhiban selectivamente el crecimiento de bacterias competidoras, incluyendo otros actinomycetes ${ }^{31}$.

Las pruebas de antagonismo demostraron que de las 62 cepas de actinomycetes aislados, 36 tuvieron actividad antimicrobiana, en donde la mayoría de los casos positivos fue contra $B$ subtilis (37,1\%) y C albicans (16,1\%). Estos resultados son prometedores si se considera que los antimicóticos de uso clínico son escasos, las candidiasis y micosis causadas por hongos dematiáceos constituyen enfermedades emergentes y en general tienen creciente importancia como agentes oportunistas en pacientes inmunocomprometidos e incluso inmunocompetentes, a lo cual hay que agregar el incremento de la resistencia al escaso número de antifúngicos existentes ${ }^{33}$.

La actividad de los actinomycetes aislados aquí sobre S aureus $(12,9 \%)$ parece muy exigua en relación a lo reportado por Pisano et al, quienes encontraron $50 \%$ de actividad de actinomycetes marinos contra Saureus ${ }^{34}$. En relación al porcentaje de Actinomycetes activos contra E coli $(12,9 \%)$, se reafirma lo comunicado por otros autores $^{34,35}$. Con respecto a la actividad antifúngica, Pisano et $\mathrm{al}^{36}$ informaron que los aislamientos de actinomycetes marinos eran activos contra levaduras (Candida kruzei 49\% y C albicans 32\%) 
y hongos filamentosos como Aspergillus niger, Trichoderma viride y Fusarium moniliforme, atribuyendo la actividad antifúngica principalmente a polienos como heptaenos. Otros autores como Jiang y $\mathrm{Xu}^{17}$ en lagos de Yunan en China y García-Quintana et $\mathrm{al}^{26}$ en suelos de la X región de Chile, informaron acerca de la actividad en contra de hongos filamentosos como Aspergillus niger y Trichophyton mentagrophytes.

Algunas cepas aisladas, como el Streptomyces LRI-4A y la Micropolyspora LRI-1A exhibieron un amplio espectro de inhibición, tanto sobre Gram negativos, Gram positivos y C albicans. Ello puede significar que el agente activo no es muy específico en cuanto a su diana, ya que actúa igualmente sobre procariontes y eucariontes, o bien, que dichas cepas nativas elaboren más de un producto, cada uno de los cuales puede tener un sitio blanco específico distinto.

También es destacable la actividad que mostró el aislamiento LRI-2A, correspondiente a una

\section{REFERENCIAS}

1. KunIN CM. Resistance to antimicrobial drugs a worlwide calamity. Ann Int Med 1993; 118: 557-61.

2. Neu HC. The crisis in antibiotic resistance. Science 1992; 257: 1064-73.

3. СоHеN ML. Epidemiology of drug resistance: Implications for a post antimicrobial era. Science 1992; 257: 1050-5.

4. Contreras L, Fica A, Figueroa O, Enrílouez N, UrRutia P, HerRera P. Resistencia de Streptococcus pneumoniae a penicilina y su asociación con factores clínicos y epidemiológicos. Rev Méd Chile 2002; 130: 26-34.

5. Stephenson J. Investigators seeking new ways to stem rising tide of resistant fungi. J Am Med Ass 1997; 277: 5-6.

6. Kontoyiannis DP, Lewis RE. Antifungal drug resistance of pathogenic fungi. Lancet 2002; 359: 1135-44.

7. Hudson MMT. Antifungal resistance and over the counter availability in the UK: a current perspective. J Antimicrob Chemother 2001; 48: 345-50. cepa de Micromonospora spp, el cual actuó sobre $\mathrm{C}$ albicans. Recientemente se ha informado que a partir del género Micromonospora se han obtenido importantes antibióticos tales como aminociclitoles (eg gentamicinas y sisomicinas), macrólidos (mycinamicina y rosamicina) y antibióticos polisacáridos (everninomicina) ${ }^{37}$.

Del total de cepas activas se eligieron 13 para la extracción de los principios activos (12 Streptomyces spp y una Micropolyspora spp). El extracto que presentó mayor actividad fue el obtenido con etilmetilcetona con $29,2 \%$ del total de los casos positivos, en tanto que la menos activa fue la extraída con cloroformo (11,5\%). Estos ensayos constituyen un paso previo a la purificación y posterior determinación de la estructura química del metabolito ${ }^{13}$.

Futuros estudios de este tipo señalarán si el antagonismo encontrado contra bacterias y hongos se debe a nuevos antibióticos.

8. Bonn D. New antifungals make mayhem for mycoses. Lancet 1997; 350: 870.

9. FenICAL W. Chemical studies of marine bacteria: developing a new resource. Chem Rev 1993; 93: 1673-83.

10. CRoss T. Aquatic Actinomycetes: A critical survey of the ocurrence, growth and role of Actinomycetes in aquatic habitats. J Appl Bacteriol 1981; 50: 397-423.

11. NiEMI RM, KNUTH S, Lundström K. Actinomycetes and fungi in surface waters and in potable water. Appl Environ Microbiol 1982; 43: 378-88.

12. Zaitlin B, Watson SB, Dixon J, Steel D. Actinomycetes in the Elbow river basin, Alberta, Canada. Water Qual Res J Canada 2003; 38: 115-25.

13. Jensen PR, FENICAL W. Strategies for the discovery of secondary metabolites from marine bacteria: Ecological perspectives. Annu Rev Microbiol 1994; 48: 559-84.

14. Leiva S, García-Quintana HG, Zaror L Actinomycetes acuáticos: una revisión sobre su aislamiento, distribución y potencial antibiótico. Medio Ambiente 2000; 13: 80-8. 
15. Hentschel U, Schmid M, Wagner M, Fieseier L, GERNERT C, HACKER J. Isolation and phylogenetic analysis of bacteria with antimicrobial activities from the Mediterranean sponges Aplysina aerophoba and Aplysina cavernicola. FEMS Microbiol Ecol 2001; 35: 305-12.

16. Cragg GM, Newman DJ. Medicinals for the millennia. The historical record. Ann NY Acad Sci 2001; 953: 3-25.

17. Jiang CL, Xu LH. Diversity of aquatic Actinomycetes in lakes of the middle plateau, Yunnan, China. Appl Environ Microbiol 1996; 62: 249-53.

18. Bavestrelo L, Cabelo A, Casanova D. Impacto de medidas regulatorias en la tendencia de consumo comunitario de antibióticos en Chile. Rev Méd Chile 2002; 130: 1265-72.

19. PisAno MA, SOMmer MJ, López M. Application of pretreatments for the isolation of bioactive Actinomycetes from marine sediments. Appl Microbiol Biotechnol 1986; 25: 285-8.

20. Takisawa M, Colwell RR, HiL RTT. Isolation and diversity of Actinomycetes in the Chesapeake Bay. Appl Environ Microbiol 1993; 59: 997-1002.

21. KüsTER E, WIwAMs ST. Selection of media for isolation of Streptomycetes. Nature 1964; 202: 928-9.

22. Holt JG, Krieg NR, Sneath PHA, Staley JT, Wiшums SP. Bergey's manual of determinative bacteriology. $9^{\text {th }}$ ed. Williams \& Wilkins, Baltimore 1994.

23. Zaror L, Espinel-Ingroff A. Pruebas de susceptibilidad fúngica frente a antimicóticos. Bol Micol 1989; 4: 77-90.

24. RoubiLARD S. Separación y purificación de un antibiótico producido por Streptomyces sp. Anal Quím Farm 1967; 9: 101-4.

25. Lazo W. Notas micológicas y bacteriológicas. Basidiomycetes y Streptomyces de Chile. Bol Micol 1991; 6: 41-2.

26. García-Quintana HG, Zaror L, Leiva S. Efecto antibiótico de cepas silvestres de Streptomyces aisladas de suelos chilenos. Rev Méd Chile 1997; 125: 1157-64.
27. Crawford DL, Lynch JM, Whipps JM, Ousley MA. Isolation and characterization of Actinomycete antagonists of a fungal root pathogen. Appl Environ Microbiol 1993; 59: 3899-905.

28. Xu LH, LI QR, JiAng CL. Diversity of soil Actinomycetes in Yunnan, China. Appl Environ Microbiol 1996; 62: 244-8.

29. LeE JY, Hwang BK. Diversity of antifungal Actinomycetes in various vegetative soils of Korea. Can J Microbiol 2002; 48: 407-17.

30. Barakate M, Ouhdouch $\mathrm{Y}$, Oufdou K, Beauleu C. Characterization of rhizospheric soil streptomycetes from Moroccan habitats and their antimicrobial activities. World J Microb Biot 2002; 18: 49-54.

31. Nolan RD, CRoss T. Isolation and screening of actinomycetes. In: Goodfellow M, Williams ST, Mordarsky M, ed. Actinomycetes in biotechnology. San Diego, Calif.: Academic Press Inc, 1988; 132.

32. Wohl DL, McArthur JV. Actinomycete flora associated with submersed freshwater macrophytes. FEMS Microbiol Ecol 1998; 26: 135-40.

33. Pujol I, Aguilar C, Gene J, Guarro J. In vitro antifungal susceptibility of Alternaria spp and Ulocladium spp. J Antimicrob Chemother 2000; 46: 337-8.

34. Pisano MA, Sommer MJ, Brancaccio L. Isolation of bioactive Actinomycetes from marine sediments using rifampicin. Appl Microbiol Biotechnol 1989; 31: 609-12.

35. Barcina I, IrIBERRI J, Egea L. Enumeration, isolation and some physiological properties of Actinomycetes from sea water and sediment. System Appl Microbiol 1987; 10: 85-91.

36. Pisano MA, Sommer MJ, Taras L. Bioactivity of chitinolytic Actinomycetes of marine origin. Appl Microbiol Biotechnol 1992; 36: 553-5.

37. Lazzarini A, Cavaletti L, Toppo G, Marinelli F. Rare genera of Actinomycetes as potential producers of new antibiotics. Antonie van Leeuwenhoek 2000; 78: 399-405.

Agradecimientos

Deseamos agradecer al Sr. Raúl Arriagada del Instituto de Zoología de la Universidad Austral de Chile, por su valiosa ayuda en la recolección de las muestras en terreno. Este estudio fue financiado por los proyectos DID S-1999-33 y DID S-2002-26. 